\title{
Effects of Mollusk Size on Growth And Color of Cultured Half-Pearls From Phuket, Thailand
}

Kannika Kanjanachatree, Napapit Limsathapornkul, Amorn Inthonjaroen, and Raymond J. Ritchie

The pearl mollusk Pteria penguin is popular for the production of half-pearls (mabe or cultured blister pearls). Research was carried out on two shell size classes implanted with half-pearl nuclei: the standard 140-145 mm size class $(n=200)$ was the control, and the smaller $130-135 \mathrm{~mm}$ size class $(n=200)$ was the test group. The mollusks were hung on strings at a sea depth of $2 \mathrm{~m}$ for up to 10 months. Implant rejection rates for the two mollusk groups were not significantly different, but the small mollusks had much lower mortality and grew faster. Nacre growth was not significantly different. Digital spectral analysis showed that the three red-greenblue (RGB) colors of the cultured half-pearls followed independent sinusoidal seasonal patterns with time periods of about $10 \pm 0.3$ months. The amplitude of variation in the RGB colors of the cultured half-pearls were all larger in the small pearl mollusks.

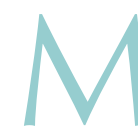

ost of the pearl farms in Phuket, Thailand, use Pteria penguin (Röding, 1798) to produce half-pearls (Kanjanachatree et al., 2003, 2019|. These typically have a cream and white color (figure 1), but the mollusk also produces yellow pearls, black half-pearls, and bicolor half-pearls (Shor, 2007). The major determining factor in the viability of the cultured half-pearl industry is consistent production of good-quality half-pearls as demanded by the market (Ky et al., 2014a,b). Research is needed to improve quality and consistency. In addition to size, thickness, and weight, consideration should also be given to the luster, darkness, shape, and visible color. The color of pearls is defined by two main criteria: the overall bodycolor of the pearl, a combination of many pigments; and secondary color that is due to refraction and wavelength interference effects, with some colors scattered on the pearl surface (Karampelas et al., 2011; Abduriyim, 2018). Some pearls are bicolor (white and yellow or black and yellow) (Kanjanachatree et al., 2019). The factors that contribute to different colors are the mollusk species, pearl thickness, water quality of

See end of article for About the Authors and Acknowledgments.

Gems \& Gemology, Vol. 55, No. 3, pp. 388-397,

http://dx.doi.org/10.5741/GEMS.55.3.388

(C) 2019 Gemological Institute of America the pearl farm, plankton density (food quality and quantity) (Snow et al., 2004; Shor, 2007), and the genetics of the mollusk population (Ky et al., 2014a,b, 2018).

\section{In Brief}

- Color development of half pearls in Pteria penguin in small and standard-sized mollusks was followed over 10 months. The smaller mollusks grew faster and had better nacre growth.

- RBG (red-green-blue) color analysis showed that the colors of the half-pearls varied during development following sine curves.

- The sinusoidal curves of red, green, and blue colors were out of phase, and so the overall color varied with age and size class of the host mollusk.

- The periodicity of color development has important consequences for color-matching of half-pearls.

Plankton are small organisms that float freely in the water. Almost all types of algae, including some bacteria and molds, are also present. Zooplankton consist of single- and multi-celled organisms, including small invertebrates, and also include the larvae of fish and invertebrates. Phytoplankton are small single-celled or multi-celled or colonial algae. They are the most abundant of all plankton and the major 


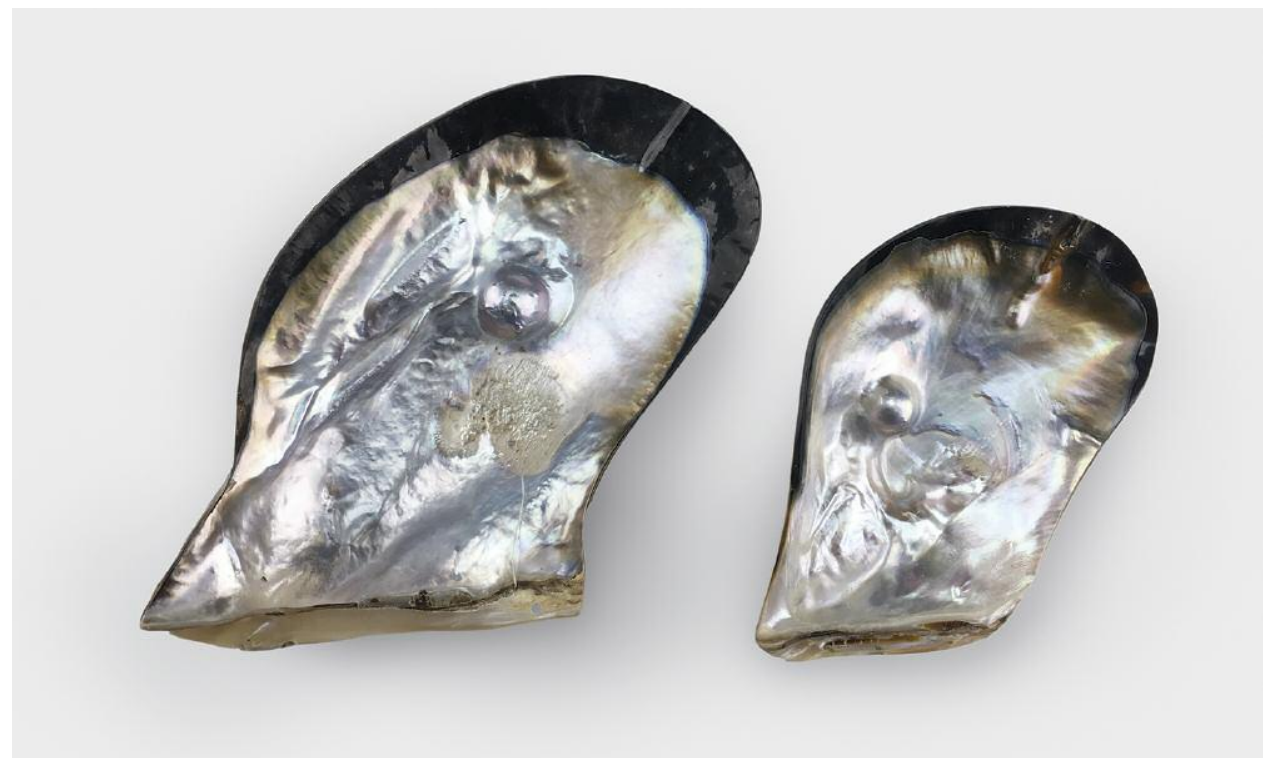

Figure 1. Cultured halfpearls from differentsized Pteria penguin mollusks. Photo by Kannika Kanjanachatree.

photosynthetic primary producers in marine ecosystems (Falkowski and Raven, 2007). They float in the water freely, but there are some mobile species with flagella. Although some are large enough to see with the naked eye, most are well below this in size. Phytoplankton use solar energy to fix inorganic carbon and convert nutrients. The primary photosynthetic pigment, chlorophyll $a$, is routinely measured to indicate the biomass of phytoplankton in water (Falkowski and Raven, 2007; Kanjanachatree et al., 2019).

The purpose of this research was to find ways to increase the overall production and value of cultured half-pearls. We set out to determine the optimum mollusk size and compare the rejection rate, the mortality rate of the seeded mollusks, and the color and quality of the cultured half-pearl, particularly any changes in the quality of the color from month to month in the cultivation of Pteria penguin.

\section{MATERIALS AND METHODS}

Collection and Sorting of Mollusks. A batch of more than 400 wild mollusks were collected from the Sapum Bay area of Phuket, near the pearl farm, in August 2015. In Phuket, this is the middle of the wet season. They were measured for overall length and divided into two classes. Based on the breeding seasons for Pteria penguin, these young mollusks were probably all 2-2 $1 \frac{1}{2}$ years of age (Milione and Southgate, 2012; Kanjanachatree et al., 2019).

Of these, 200 pearl mollusks were designated the large or standard mollusk class, measuring 140-145 $\mathrm{mm}$ in length. Because this is the size class typically used for half-pearl cultivation, we made this the control group (figure 2). The second class consisted of 200 smaller mollusks, measuring $130-135 \mathrm{~mm}$ in length. These formed the test group for the experiment.

Implantation Procedure. Half-pearl nuclei $(17 \mathrm{~mm}$ diameter) were implanted in August 2015, and the experiment was run for 10 months. Standard half-pearl cultivation practices were followed as described by Taylor and Strack (2008) and in our previous publications (Kanjanachatree et al., 2003, 2019). The mollusk was left in the air for 30 minutes, or in

Figure 2. Different size classes of Pteria penguin pearl mollusks: small (130-135 mm) and standard (140 $145 \mathrm{~mm})$. Photo by Kannika Kanjanachatree.

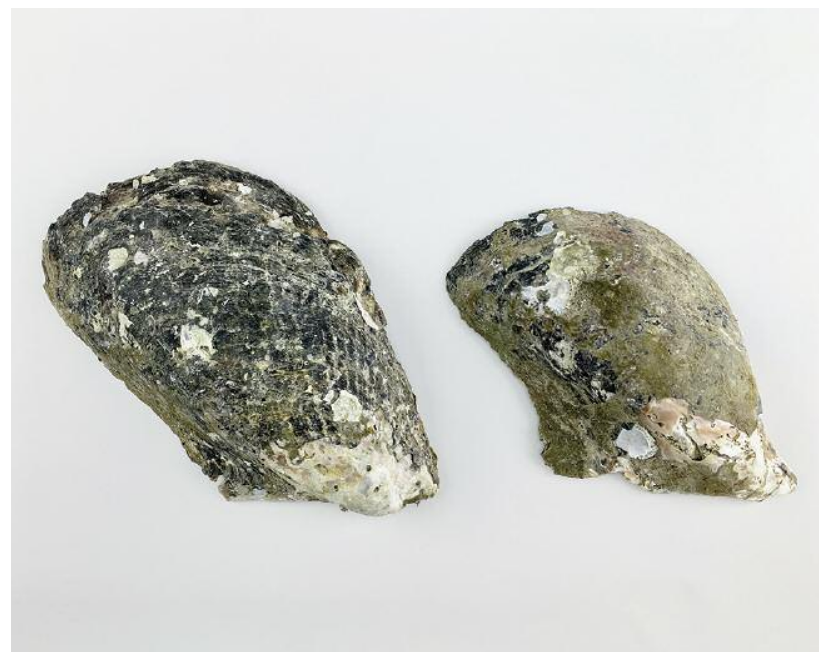



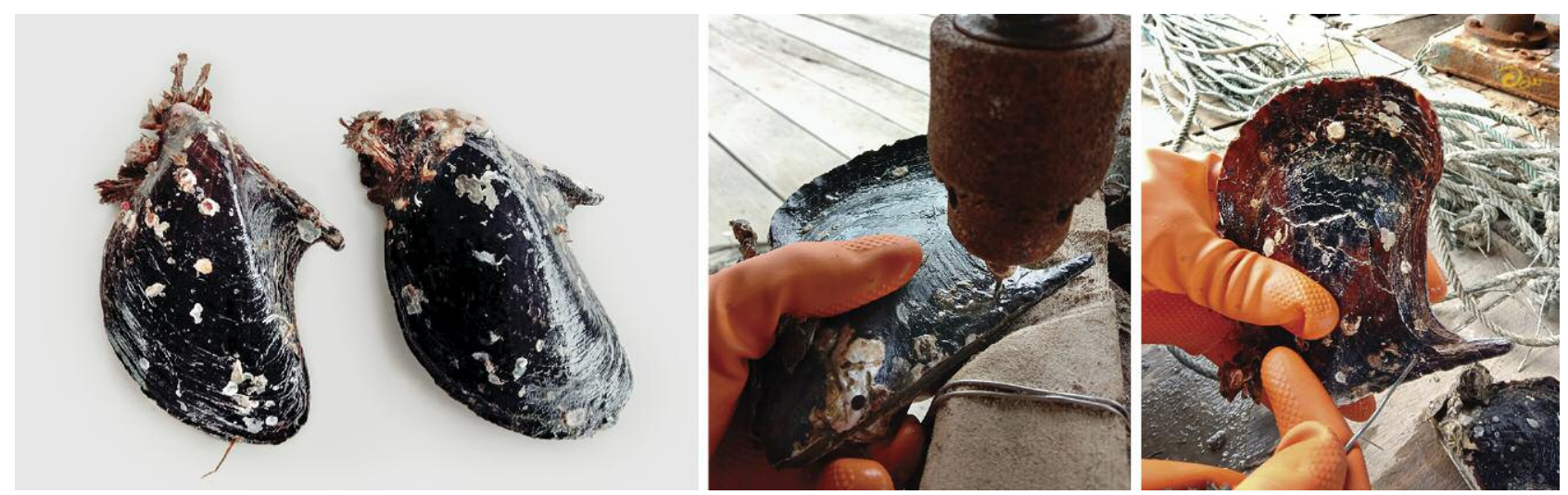

Figure 3. Drilling shells for hanging mollusks on strings: a pearl mollusk prepared for drilling (left), the drilling procedure (center), and the stringing (right). Photos by Kannika Kanjanachatree.

continuously running seawater. Shells began to open, and then a small wooden wedge was inserted into the mollusk to hold it open (Shor, 2007). Shells were placed in a clamp, pliers were used to insert the speculum, and the mollusk was held open using a metal spatula. The nucleus is made from resin and has a base length of $17 \mathrm{~mm}$. It is attached to the shell with a glue containing ethyl-2-cyanoacrylate. Nuclei were placed near the adductor muscle in the standard position used for mabe (cultured blister) half-pearls.

A small hole was drilled in each shell so the mollusks could be hung in the water in strings, two me- ters below the surface to avoid excessive sunlight (figures 3 and 4). Mollusks also receive a larger amount of plankton at this depth (Kanjanachatree et al., 2003). All mollusks were checked each month and scrubbed to remove fouling organisms (Taylor and Strack, 2008). Harsher methods for removing fouling organisms were avoided.

Assessment of Growth of Cultured Half-Pearls, Food Resources, and Half-Pearl Quality. Ten mollusks were randomly selected each month for assessment. These mollusks were removed from the experiment,

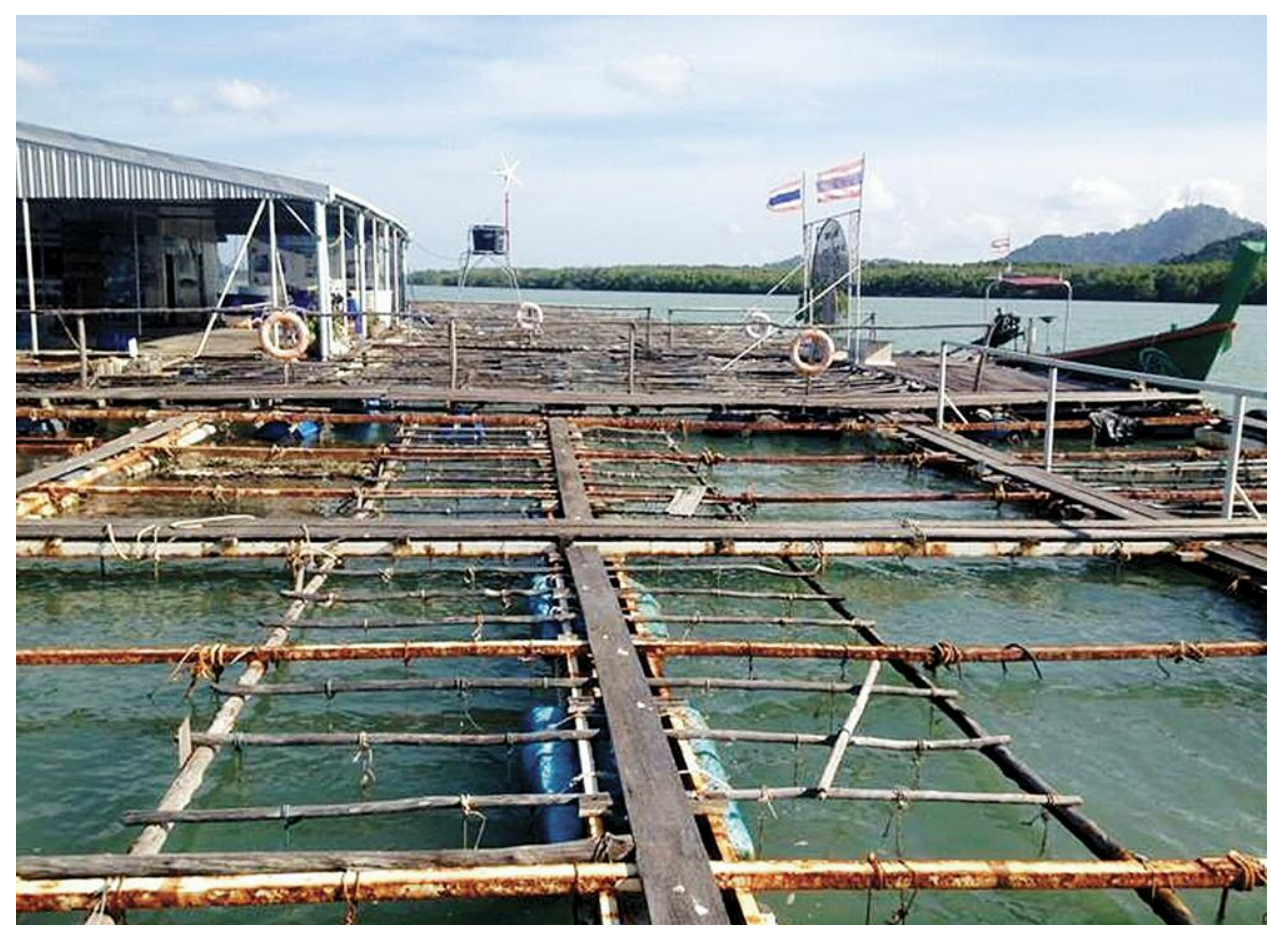

Figure 4. Preparation and hanging the mollusks on strings two meters below the water's surface on the floating raft pearl farm. Photo by Kannika Kanjanachatree. 
so the cohort decreased from 200 at month 0 to 100 at month 10. In our previous study (Kanjanachatree et al., 2019) the parameters could be measured nondestructively and the mollusks were returned to the water, but the measurements made in the present study necessarily involved the death of the mollusks.

The assessed parameters were mortality, rejection of nucleus by the mollusk, half-pearl nacre formation, pearl nacre thickness, and growth of shell from the differently sized Pteria penguin mollusks. Data were recorded over the 10 months of the project (mean $\pm 95 \%$ confidence limits, $\mathrm{n}=10$ ).

Chlorophyll Analysis. Chlorophyll measurements were made on water samples taken for the environmental monitoring. The water samples were collected from the pearl farm at four points to determine the average chlorophyll and carotene content. Cells were filtered using standard $0.45 \mu \mathrm{m}$ filter disks. Chlorophyll was assayed using a formula for a mixed phytoplankton population (Ritchie, 2006) using ethanol solvent and a Shimadzu UV-1601 UV-visible dual beam spectrophotometer. Water sample volumes were $500 \mathrm{~mL}$. Chlorophyll content was expressed as $\mu \mathrm{g} / \mathrm{L}$ of water sample. The monthly results (see supplementary table 1 at https://www.gia.edu/ doc/FA19-Phuket-Half-Pearls-SupplementaryTable1.pdf) were similar to those published previously in Kanjanachatree et al. (2019).

Color of Cultured Half-Pearls. There has been a resurgence of interest in quantitative color analysis of pearls (Ky et al., 2014a,b, 2018), particularly as a result of the finding that selective breeding for color is possible. The color of the half-pearls was measured using the method and simple apparatus described by Choodum et al. (2014) for use on drug samples. The device uses readily accessible mobile phone technology for digital image analysis of red, green, and blue (RGB) light. The device is a simple light box fitted with a white LED light source and constructed using minimal equipment, as opposed to an integrating sphere scanning spectrophotometer that is highly specialized and not readily available. The measured colors of the half-pearls were compared month to month and compared to a set of cultured half-pearl standard colors (Phuket Pearl Industry Standards).

Statistical Analysis. Completely randomized design data were analyzed by one-way analysis of variance (ANOVA), and comparisons of mean values were made using Duncan's new multiple range test (DMRT) using standard statistical analysis packages. The confidence level of $\mathrm{p}<5 \%$ was chosen as the significant difference criterion. Samples with the same superscript letter were not significantly different $(\mathrm{p}$ $<0.05$ ). Standard linear regression methods were used to fit linear regressions $(\mathrm{Y}=\mathrm{mx}+\mathrm{b})$ to data. The seasonal sinusoidal fit to the half-pearl color data was performed using non-linear least squares methods, and the asymptotic errors of the fitted parameters were calculated by matrix inversion. The standard statistical reference text used was Snedecor and Cochran (1980).

\section{RESULTS AND DISCUSSION}

Water Quality and Chlorophyll Content Over the Course of This Study. Phuket has a wet maritime monsoonal climate, with a wet season from April to November each year (about $300 \mathrm{~mm} / \mathrm{month}$ ) and a dry season the rest of the year (about 100 $\mathrm{mm} / \mathrm{month}$ ) (Kanjanachatree et al., 2019). The dry season drought is therefore not as severe as in mainland Asia. The study was begun in August and continued over 10 months, so it extended from the middle of the wet season to the beginning of the next wet season. During the monthly monitoring of the mollusks, midday measurements were made of Secchi depth $(\mathrm{cm})$, air temperature $\left({ }^{\circ} \mathrm{C}\right)$, surface water temperature $\left({ }^{\circ} \mathrm{C}\right)$, salinity in parts per thousand $(\%)$, and $\mathrm{pH}$ using standard methods for measurements of water and wastewater (Cleseri et al., 1998, known as the APHA manual). Similar monthly results have been published previously in Kanjanachatree et al. (2019). Overall, the results in the present study were very uniform, with little seasonality in the five parameters of water quality just mentioned, so overall values were calculated (see supplementary table 2 at https://www.gia.edu/doc/FA19-Phuket-Half-PearlsSupplementary-Table2.pdf). The calculated values compared well with previous environmental data for the study site (Kanjanachatree et al., 2019). The Secchi disk depth was $106 \pm 12 \mathrm{~cm}$, the water temperature was $29 \pm 0.8^{\circ} \mathrm{C}$ (range of $26-32^{\circ} \mathrm{C}$ ), the salinity was $30 \pm 0.5$ ppt (range of $27-35 \mathrm{ppt}$ ), and the dissolved oxygen was typically high $(5.63 \pm 0.64 \mathrm{mg} / \mathrm{L} \approx$ $87 \%$ saturation, range of 5.2-7.3), and the overall $\mathrm{pH}$ was typical for seawater (8.3). Seawater becomes more acidic when $\mathrm{CO}_{2}$ levels are high and more alkaline when phytoplankton remove $\mathrm{CO}_{2}$. There was very little seasonality of conditions at the study site compared to other pearl-growing areas in more tem- 


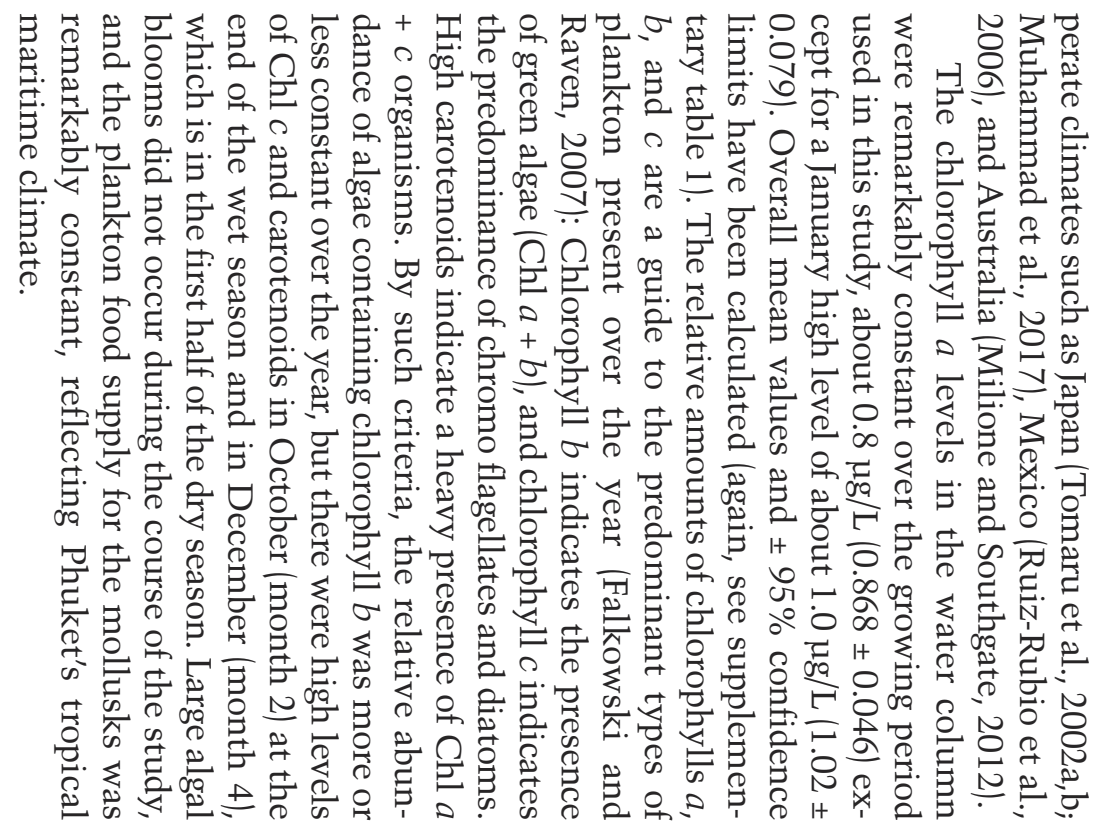

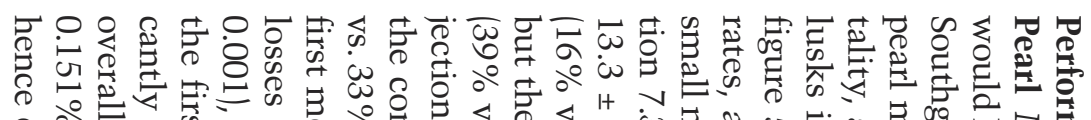

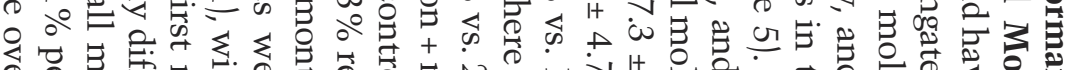

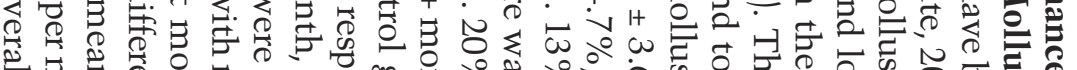

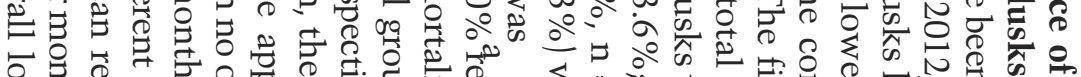

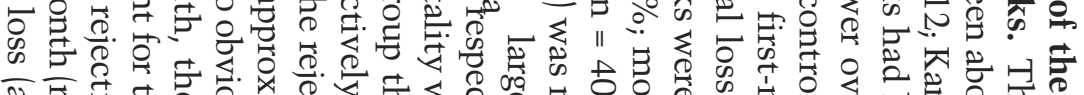

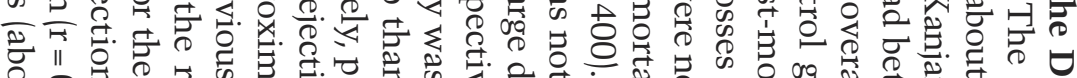

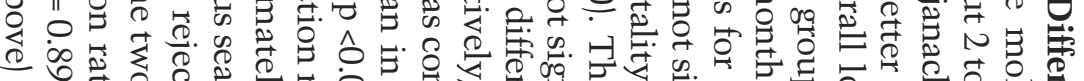

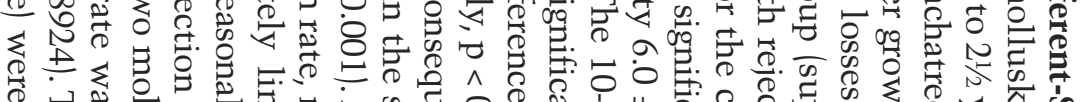

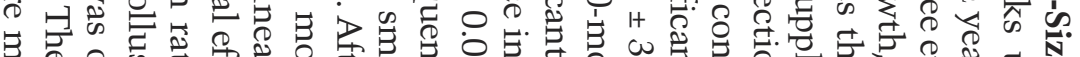

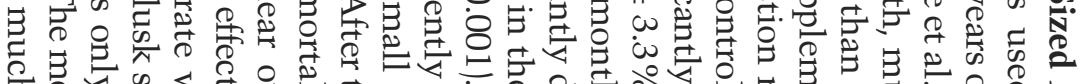

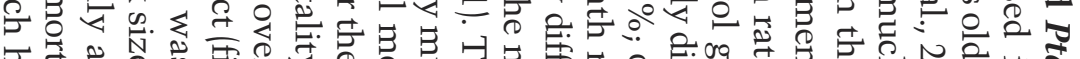

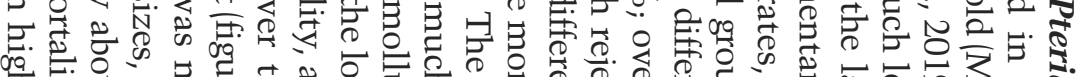

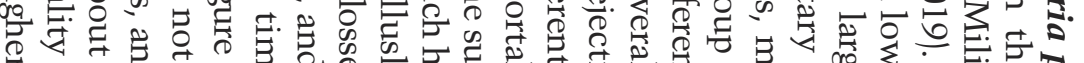

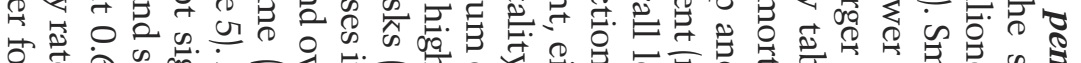

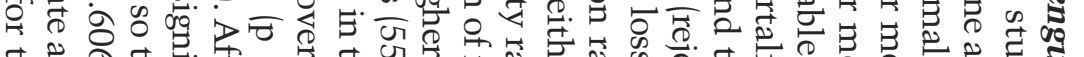

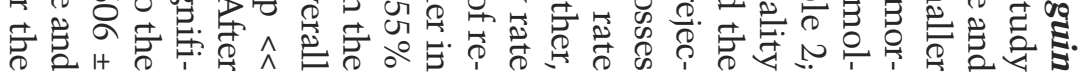

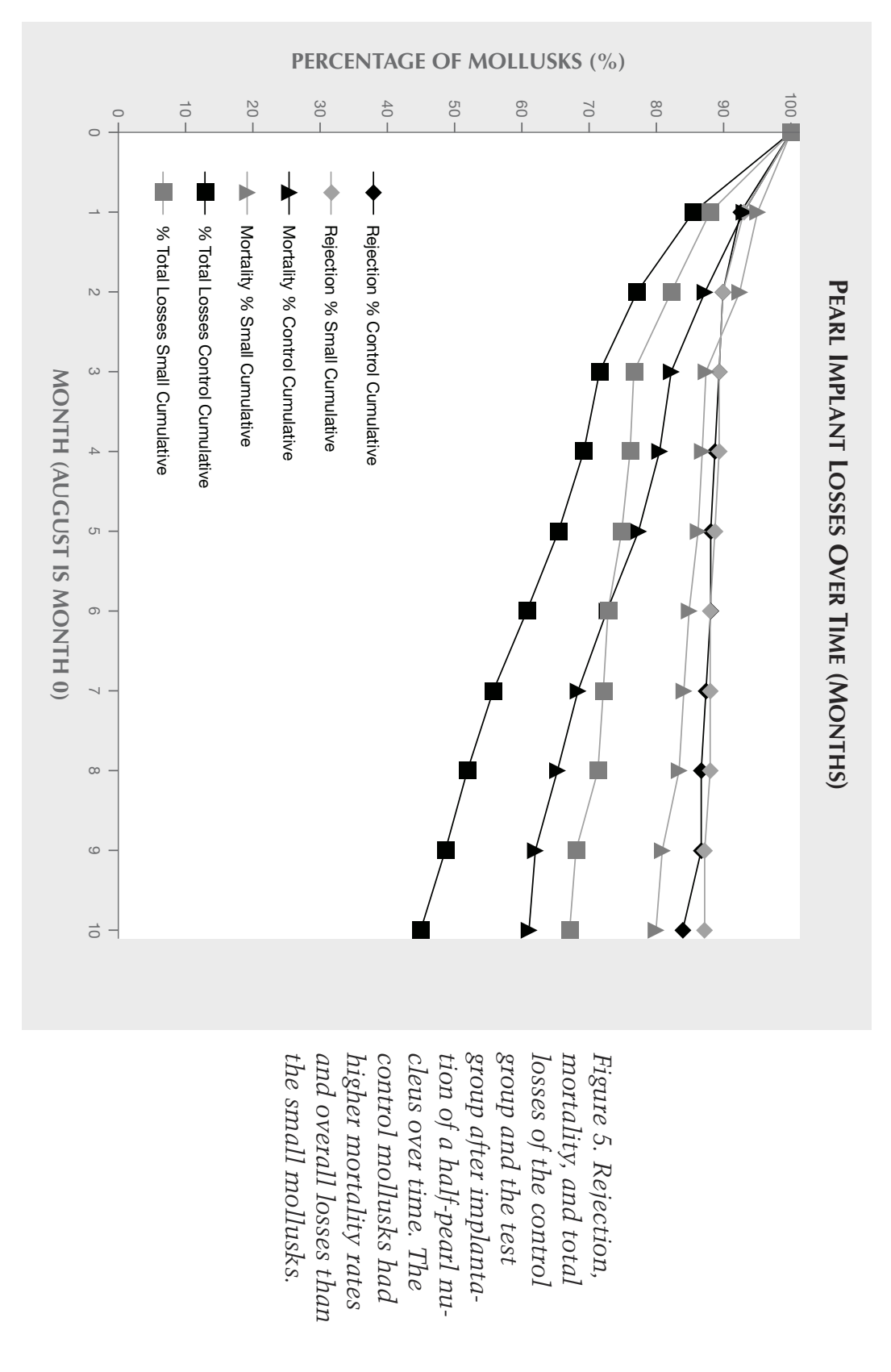


control mollusks $(3.575 \pm 0.340 \%$ per month vs. 1.490 $\pm 0.364 \%$ per month), resulting in a total loss rate of $4.288 \pm 0.389 \%$ per month $(\mathrm{r}=0.9939)$ for the control mollusks vs. $1.989 \pm 0.544 \%$ per month $(r=0.9482)$ for the small mollusks. The rejection rates, mortalities, and total losses for the control mollusks in this study are comparable to those found previously in Phuket pearl mollusks (Kanjanachatree et al., $2018 a, b)$. Growth rates of shell and half-pearls were determined by linear regression (supplementary table 2; figure 5). The shells of the small mollusks grew faster $(3.274 \pm 0.177$ vs. $2.231 \pm 0.927 \mathrm{~mm} /$ month, mean values $\pm 95 \%$ confidence limits), but their pearl nacre did not $(0.3134 \pm 0.05334$ vs. $0.2458 \pm 0.1349$ $\mathrm{mm} / \mathrm{month}$ ). The standard-sized mollusks routinely used for half-pearl farming using Pteria penguin are actually suboptimal for shell growth, though not for nacre growth of the half-pearls, but their mortality rate is unacceptably high.

Feeding. Tomaru et al. (2002a,b) studied the relationship between akoya pearl mollusks and chlorophyll $a$ concentration in phytopigment extracts of the wet mollusk tissue (basically a measure of the stomach contents) and the dry tissue weight in the pearl mollusks at Ago Bay (1967-1969) and Ohmura Bay (1984-1985) in Japan. Their study showed that the concentration of chlorophyll $a$ as a measure of the mollusks' diet affected their growth and growth of the implanted pearls. However, Japan has a temperate climate with four distinct seasons and a spring plankton bloom, and so plankton availability was much more seasonal than in Phuket. The dry season in Phuket is not a period of extreme drought as it is in many monsoonal climates: There is at least some rain all year.

Pearl mollusks feed by filtration, either of live food or dead food. Sometimes they absorb dissolved organic matter (DOM), but the importance of this as a source of nutrition has not been well documented or quantified. Very small plankton (picoplankton, $\approx 1$ $\mu \mathrm{m})$ are very important to pearl mollusks. They feed on other picoplankton and nanoplankton much smaller than the effective mesh size of their filtration apparatus because their gills are covered in a sticky mucus that traps nanoplankton (Tomaru et al., 2002a). Bacteriastrum, Leptocylindrus, Melosira, Nitzschia, Rhizoslovenia, Skeletonema, Thalassionema, and Thalassiosira are all consumed by the mollusks (Martinez-Fernandez et al., 2006). Some of these species were found at the Phuket pearl farm, but the more common species were the diatoms
Chaetoceros and Skeletonema, which are generally regarded as non-toxic. Some species such as the Nitzschia species are also blamed for shellfish food poisoning and mortality. Where Nitzschia were found in large quantities and for a prolonged period of time, the mortality rate of the shellfish was found to increase. Tomaru et al. (2002a) reported that the Nitzschia species that bloomed in a bay in Japan's Uchiumi Prefecture caused the death of akoya pearl mollusks in 1998. Nitzschia contains chlorophyll $a$ $+b$, so such blooms would be indicated by very high levels of Chl $a+b$, which did not occur at the Phuket pearl farm during this study (Kanjanachatree et al., 2018a,b). Similarly, other harmful blooms are often caused by dinoflagellates, which have high levels of chlorophyll $a+c$ and high carotenoids. See Tun (2000), Shor (2007), and Taylor and Strack (2008) for overviews of mass mortalities in pearl mollusks and their consequences.

Temperature. The present study measured the water quality of the pearl farm, which was within the standard for aquaculture in Thailand. Conditions on the farm, with a temperature range of $26-32^{\circ} \mathrm{C}$, do not cause death of the mollusks (Kanjanachatree et al., 2019). This is consistent with the study of Tomaru et al. $(2002 \mathrm{a}, \mathrm{b})$ on Japanese pearl farms that have a temperate climate. At temperatures above $20^{\circ} \mathrm{C}$, food availability and metabolism increase and have positive effects on shell thickness, but this does not affect the size of the shells. Yukihira et al. (2000) reported that at temperatures below $12^{\circ} \mathrm{C}$, akoya pearl mollusks (Pinctada fucata) in Nagoya have reduced nacre secretion, which affects the production of pearls and reduces the weight of the shellfish. But at either $7.5^{\circ} \mathrm{C}$ or $35^{\circ} \mathrm{C}$, the mollusks ate less. Eventually, excessively cold or hot temperatures stop both the movement of the cilia and the heartbeat of mollusk larvae. But the response to temperature depends on the stage of the larva. High temperatures make mollusks more vulnerable to disease by increasing their stress levels, making them less able to cope with infections (Mannion, 1983).

Mollusks are ectothermic animals, so the ambient temperature affects their metabolism and survival rate. Metabolism affects respiratory processes, absorption, excretion, and growth of tissues, as well as reproductive cells and vulnerability to diseases. Higher temperatures are not always good; usually there is an optimum temperature, and higher temperatures are progressively harmful. High temperatures can destroy enzymes (Yukihira et al., 2000) and 
promote diseases in pearl mollusks (Mannion, 1983). High-temperature fatalities in aquatic organisms are often a consequence of oxygen stress because $\mathrm{O}_{2}$ solubility decreases with temperature (Yamamoto et al., 1999; Yukihira et al., 2000). Water temperatures at the Phuket pearl farm are exceptionally stable throughout the year, with no sudden cold or hot events (Kanjanachatree et al., 2019). Temperatures of $7.5^{\circ} \mathrm{C}$ and $35^{\circ} \mathrm{C}$ (Yukihira et al., 2000) are both outside the range found at the Phuket pearl farm.

Fouling of cultivated pearl mollusks is an expensive nuisance (Dharmaraj et al., 1987; O'Connor and Newman, 2001; Guenther et al., 2006). In the present study, a monthly scrubbing was sufficient to prevent overgrowth by fouling organisms. Salinity changes are often used to control nuisance fouling organisms. Salinities outside the normal seawater range are generally fatal. In a study by Dharmaraj et al. (1987), pearl mollusks at Veppalodai, India (Gulf of Mannar), had $100 \%$ mortality at salinities of $14 \%$, $55 \%$, and $58 \%$. The mollusks were resistant to salinity ranges of $17-$ $45 \%$, had a mortality rate of $0 \%$, and could withstand fatal salinities for very brief periods by tightly closing their shells. Encrustations of fouling invertebrates and unwanted algae can be killed by soaking akoya mollusks in fresh water for 15 minutes. Brines (saltwater $60 \%$ ) can be used to kill Polydora ciliates and tubeworms (O'Connor and Newman, 2001). The mollusks lack access to oxygen when their shell lid is tightly closed. Pinctada sugillata from the Gulf of Mannar (India) are resistant to low oxygen levels for up to 2427 hours (Dharmaraj et al., 1987). Low-oxygen stress leads to glycolytic acid accumulation in tissues. Yamamoto et al. (1999) reported that low oxygen levels in rapidly growing plankton blooms encourage the growth of dinoflagellates. The pearl farm in their study had a dense planting of mollusks. There were high suspended solids after heavy rain, some minor pollution, and limited circulation in deeper water. Water temperatures at the Phuket pearl farm are sometimes as high as $>32^{\circ} \mathrm{C}$ (Kanjanachatree et al., 2019), but mass mortalities are rare in Phuket and similar locales (Tun, 2000). All of the factors mentioned above can result in reduced oxygen levels, leading to physiological stress. Extreme treatments to control fouling are best avoided if possible because they are likely to interfere with shell growth and nacre formation. The overall loss rate of Pteria penguin mollusks with implanted half-pearls was already high (figure 5). Any activities that might increase mortality are best avoided since they would make cultivation uneconomical (Kanjanachatree et al., 2019).
Phuket has two tidal cycles a day, so there is a continuous flow of water at the pearl farm. But because it is a floating raft, the depth at which the mollusks were suspended was constant. The farm is located in a strait behind a barrier island and has a very favorable circulation pattern, so the environmental conditions there are never unfavorable (Kanjanachatree et al., 2019) and mass mortalities are rare. The water quality at the pearl farm easily met the physical and chemical standards for aquaculture in Thailand (Yukihira et al., 2006). The water currents allowed the pearl mollusks to receive oxygen and filter feed. During the breeding season, the currents also help spread the reproductive cells and larvae of the shellfish. But during the low tide, the water carried by currents from the coastline was turbid, which may cause sediment to accumulate on the shell. The decrease in plankton and oxygen levels at low tide can cause the mollusk to become temporarily deprived of oxygen (Condie et al., 2006), but this was not a problem at the Phuket pearl farm, which is in a well-circulated site and located on a floating raft in about $10 \mathrm{~m}$ of water: The farm has never had a mass mortality event (Kanjanachatree et al., 2019). Poor growth conditions seem to increase pearl secretion, resulting in a faster pearl coating, but with lower production quality (Condie et al., 2006). In addition, there are tidal effects on the diet of $P$. margaritifera in more marginal farm locations (such as enclosed bays) because it does not tolerate high suspended solids in water, whereas $P$. maxima is more resistant to turbidity (Yukihira et al., 2006).

Color Analysis of Cultured Half-Pearls. Supplementary table 3 at https://www.gia.edu/doc/FA19Phuket-Half-Pearls-Supplementary-Table3.pdf shows the color indices of the cultured half-pearls over the course of the study, and the data is plotted in figures 5 and 6 . The RGB indices showed no significant linear increase or decrease over time (linear regression: $\mathrm{y}=\mathrm{mx}+\mathrm{b}, \mathrm{p}>>0.05)$. However, there was a noticeable sinusoidal periodic difference in color over time, with maxima at months 4 and 5 (December and January) after the start of the experiment (figures 6 and 7). The effect on the blue indices is the most noticeable, with the blue indices higher in December and January at the beginning of the dry season. The \% reflectance appears to go up in the dry season and goes down in the wet season in a seasonal pattern.

A complex sinusoidal model was fitted to the RGB data by the equation: 


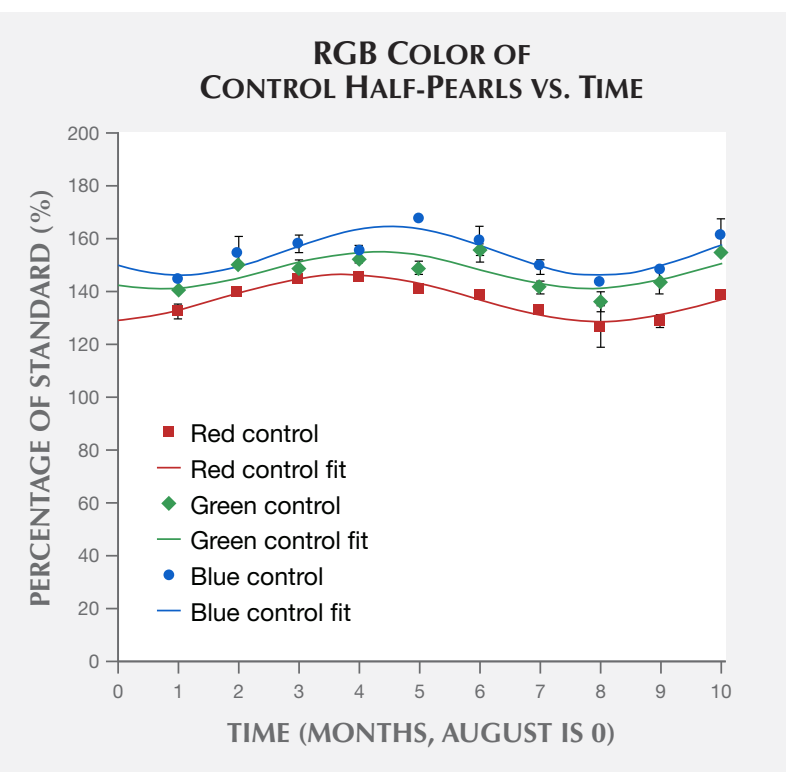

Figure 6. Cyclic nature of red-green-blue (RGB) color properties of cultured half-pearls from the control group over the course of the project. The mollusks were implanted in August, month 0.

$\mathrm{Y}=\mathrm{A} \times \operatorname{Sin}(\varpi \cdot \mathrm{T}+\mathrm{D})+\mathrm{C}$

The period for this function is:

$2 \pi=\varpi \cdot T p+D$

$\therefore \mathrm{Tp}=\frac{2 \pi-\mathrm{D}}{\omega}$

where $Y$ is the \% reflectance compared to an industry standard, $A$ is an amplitude scaling factor for the sine function, $T$ is time in months, $\omega$ is the period scaling factor ( $\omega=0.5236$ for $T$ in months), $D$ is a displacement factor for adjusting where to start the sine function, $C$ is a scaling constant (average $Y$ over the time period), and $T p$ is the repeat period of the sine function (in months). Parameters A, $\omega$, D, and C for Equation 1 could be estimated using Microsoft Excel's Solver tool, and their asymptotic errors could be estimated by matrix inversion (Snedecor and Cochran, 1980).

Figures 6 and 7 show mean values $\pm 95 \%$ confidence limits of standardized reflectance in half-pearls of standard- and small-sized mollusks over the course of the 10-month experiment starting in August 2015. The curve fits were all highly statistically significant $(\mathrm{p}<0.001)$, and all means of the fitted parameters were significantly different from zero (see analysis in supplementary table 1). The period scaling factor $(\omega)$ would have been 0.5236 if the period were exactly one year: The experimentally deter- mined $\omega$ values were all greater than $\omega=0.5236$. Only one $\omega$ value was significantly different from the others (red, control), and since the Tp value was not different, an overall value for $\omega=0.8430 \pm 0.0284$ could be calculated. The amplitude (A) of the seasonal effect was greatest in the case of the blue color of cultured half-pearls from small mollusks and least in the case of the green color index of half-pearls from the control group. The amplitude (A) was noticeably higher in the cultured half-pearls from the small mollusks for all RBG colors (figures 6 and 7; supplementary table 1 ). The range in color was nearly $\pm 30 \%$ in the case of the blue color of the half-pearls from the small group. The mean color was measured by the constant parameter (C). As would be expected, the average \% colors for red, green, and blue were significantly different, but the three colors were not significantly different when the control group and the small mollusks were compared as pairs. The displacement parameter (D) shifted the sine curve timewise to optimize the fit. On an annual scale, 0.5236 radians is equivalent to one month, and so $\mathrm{D}$ was equivalent to -2 to -5 months in most cases. If the changes in color over time were synchronous, the parameter D would not be significantly different for the different RGB colors: Supplementary table 2 shows that $\mathrm{D}$ is significantly different even though the pe-

Figure 7. Sinusoidal character of RGB color properties of the cultured half-pearls grown in small mollusks. The cyclic nature of the color of the cultured halfpearls is more apparent in the small pearl mollusks.

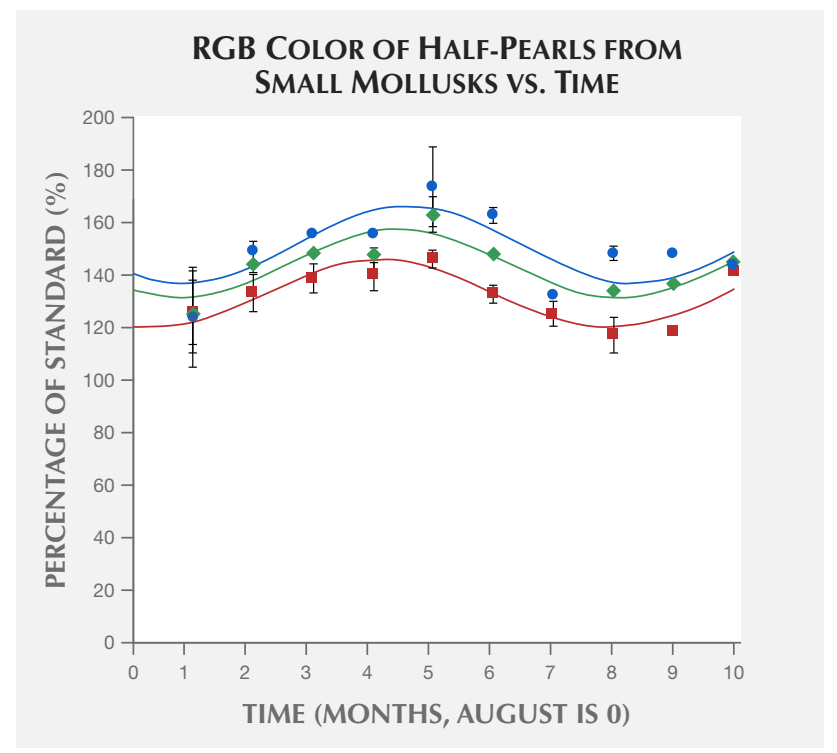


riod parameter $\omega$ was only marginally significant and the time period $(\mathrm{Tp})$ of the sine curves was not significantly different. The RGB color of the cultured half-pearls thus shows an asynchronous seasonality (figures 6 and 7). Growth of the half-pearls was linear over time (supplementary table 2). The available phytoplankton also appeared to be more or less constant, with no strong seasonality as would be found in a temperate climate (Yukihira et al., 2000, 2006; Tomaru et al., 2002a,b).

These color trends are not readily noticeable to human color matchers of pearls, but some matchers do note that there appears to be a relationship between harvest time and color. Comparison of figures 6 and 7 (supplementary table 1) shows that the seasonal sinusoidal effect is more obvious in the cultured half-pearl from the small mollusks (figure 7) than in the standard-sized group (figure 6). The seasonal effect is least apparent in green light (human eyesight happens to be most sensitive to green light). These findings are important considerations in colormatching of the pearls (Shor, 2007). The seasonal effect is nearly $\pm 30 \%$ of standardized reflectance in the case of blue color, and so would be important in color matching and in displaying the pearls for sale. Modern "white" light diodes have a very heavy blue component compared to green and red light and so are not well color balanced compared to natural sunlight or other common light sources. Hence, display cases using "white" diodes will cause differences in blue light reflectance to be more conspicuous than, for example, under typical fluorescent lighting. More sophisticated color analysis using integrating sphere technology is needed to resolve color issues of pearls, following the work of Karampelas et al. (2011) on ma- rine pearl mollusks and Abduriyim (2018) on freshwater pearl mollusks.

\section{CONCLUSIONS}

The rate of nacre deposition on half-pearl nucleus is not significantly different between small and large Pteria penguin mollusks, but there are significant RGB color differences (supplementary table 1). The growth of the mollusk contributes to the rate of halfpearl nacre deposition. In this study, the small mollusks grew faster and had a much better survival rate than the larger ones that are the industry standard (figure 5). To achieve the highest quality, the half-pearls should be harvested in the seventh month because the thickness of the nucleus plus pearl layer is up to 19.4 $\mathrm{mm}$ (nacre $1.2 \mathrm{~mm}$ thick), which is the optimum for buttons and for button-shaped jewelry. Longer incubations produce pearls of increasingly uneven shape, which are less useful for buttons and jewelry.

The RGB color of the cultured half-pearls seems to be little affected by the month if a simple linear regression is fitted to the data. However, more sophisticated analysis shows that there is a seasonal (sinusoidal) effect on color reflectance, particularly in blue light (figures 6 and 7; supplementary table 1). The smaller mollusks produced better-quality cultured half-pearls and had a lower mortality and rejection rate. However, the RGB colors of the cultured half-pearls had larger amplitudes of color variation over the incubation period than the colors in the larger pearl mollusks. The phases of the sinusoidal changes in RBG colors of the half-pearls are not inphase (synchronous), so the overall color of the pearls changes over the year. This has important consequences for color matching.
ABOUT THE AUTHORS

Ms. Kanjanachatree is an assistant professor, Ms. Limsathapornkul is a technical officer, and Dr. Ritchie is an associate professor, at Prince of Songkla University in Phuket, Thailand. Mr. Inthonjaroen is director of at Phuket Pearl Industry, Co. Ltd.

\section{ACKNOWLEDGMENTS}

The authors wish to thank Phuket Pearl Industry Co. Ltd. for providing access to the pearl farm facilities. Prince of Songkla University in Phuket provided access to equipment for analyses done as part of the study.

\section{REFERENCES}

Abduriyim A. (2018) Cultured pearls from Lake Kasumigaura: Production and gemological characteristics. $G \uplus G$, Vol. 54, No. 2, pp. 166-183, http://dx.doi.org/10.5741/GEMS.54.2.166

Choodum A., Parabun K., Klawach N., Daeid N.N., Kanatharana P., Wongniramaikul W. (2014) Real time quantitative colourimetric test for methamphetamine detection using digital and

mobile phone technology. Forensic Science International, Vol. 235, pp. 8-13, http://dx.doi.org/10.1016/j.forsciint.2013.11.018 Cleseri L.S., Greenberg A.E., Eaton A.D., Franson M.A.H., Eds. (1998) Standard Methods for the Examination of Water and Wastewater (APHA), 20th ed. American Public Health Association, Washington, DC, pp. 1189. 
Condie S.A., Mansbridge J.V., Hart A.M., Andrewartha J.R. (2006) Transport and recruitment of silver-lip pearl oyster larvae on Australia's North West Shelf. Journal of Shellfish Research, Vol. 25, No. 1, pp. 179-185, http://dx.doi.org/10.2983/07308000(2006)25\%5B179:TAROSP\%5D2.0.CO;2

Dharmaraj S., Chellam A., Velayudhan T.S. (1987) Biofouling, boring and predation of pearl oyster. In K. Alagarswami, Ed., Pearl Culture. Central Marine Fisheries Research Institute (CMFRI), Indian Council of Agricultural Research, Bulletin No. 39, Chapter 14, pp. 92-97.

Falkowski P.G., Raven J.A. (2007) Aquatic Photosynthesis, 2nd ed. Princeton University Press, Princeton, New Jersey.

Guenther J., Southgate P.C., De Nys R. (2006) The effect of age and shell size on accumulation of fouling organisms on the akoya pearl oyster Pinctada fucata (Gould). Aquaculture, Vol. 253, No. 1-4, pp. 366-373, http://dx.doi.org/10.1016/j.aquaculture. 2005.08.003

Kanjanachatree K., Piyathamrongrut K., Inthonjaroen N. (2003) Effects of sea depths and sizes of winged pearl oysters (Pteria penguin) on pearl culture. Songklanakarin Journal of Science and Technology, Vol. 25, No. 5, pp. 659-671.

Kanjanachatree K., Limsathapornkul N., Inthonjaroen A., Ritchie R.J. (2019) Implanting half-pearl nuclei in different positions in mabe pearls (Pteria penguin, Röding, 1798). Thalassas, Vol. 35, No. 1, pp. 167-175, http://dx.doi.org/10.1007/s41208-018-0106$\mathrm{x}$.

Karampelas S., Fritsch E., Gauthier J.-P., Hainschwang T. (2011) UV-Vis-NIR reflectance spectroscopy of natural-color seawater cultured pearls from Pinctada margaritifera. $G \oplus G$, Vol. 47, No. 1, pp. 31-35.

Ky C.-L., Blay C., Sham-Koua M., Vanaa V., Lo C., Cabral P. (2014a) Family effect on cultured pearl quality in black-lipped pearl oyster Pinctada margaritifera and insights for genetic improvement. Aquatic Living Resources, Vol. 26, No. 2, pp. 133-145, http://dx.doi.org/10.1051/alr/2013055

Ky C.-L., Blay C., Sham-Koua M., Lo C., Cabral P. (2014b) Indirect improvement of pearl grade and shape in farmed Pinctada margaritifera by donor "oyster" selection for green pearls. Aquaculture, Vol. 432, pp. 154-162, http://dx.doi.org/10.1016/ j.aquaculture.2014.05.002

Ky C.-L., Sham-Koua M., Gilles Le Moullac G. (2018) Impact of spat shell colour selection in hatchery-produced Pinctada margaritifera on cultured pearl colour. Aquaculture Reports, Vol. 9, pp. 62-67, http://dx.doi.org/10.1016/j.aqrep.2017.12.002

Mannion M.M. (1983) Pathogenesis of a marine Vibrio species and Pseudomonas putrefaciens infections in adult pearl oysters, Pinctada maxima (Mollusca: Pelecypoda). Thesis, Honours Degree in Veterinary Biology, Murdoch University, Australia, 130 pp.

Martinez-Fernandez E., Acosta-Salman H., Southgate P.C. (2006) The nutritional value of seven species of tropical microalgae for black-lip pearl oyster (Pinctada margaritifera, L.) larvae. Aquaculture, Vol. 257, pp. 491-503, http://dx.doi.org/10.1016/ j.aquaculture.2006.03.022

Milione M., Southgate P. (2012) Growth of winged pearl oyster, Pteria penguin, at dissimilar sites in northeastern Australia. Journal of Shellfish Research, Vol. 31, No. 1, pp. 13-20, http://dx.doi.org/10.2983/035.031.0102

Muhammad G., Atsumi T., Sunardi, Komaru A. (2017) Nacre growth and thickness of akoya pearls from Japanese and hybrid Pinctada fucata in response to the aquaculture temperature condition in Ago Bay, Japan. Aquaculture, Vol. 477, pp. 35-42, http://dx.doi.org/10.1016/j.aquaculture.2017.04.032

O'Connor W.A., Newman L.J. (2001) Halotolerance of the oyster predator, Imogine mcgrathi, a Stylochid flatworm from Port Stephens, New South Wales, Australia. Hydrobiologia, Vol. 459, No. 1-3, pp. 157-163, http://dx.doi.org/10.1023/ A:1012525015850

Ritchie R.J. (2006) Consistent sets of spectrophotometric equations for acetone, methanol and ethanol solvents. Photosynthesis Research, Vol. 89, No. 1, pp. 27-41, http://dx.doi.org/ 10.1007/s11120-006-9065-9

Ruiz-Rubio H., Acosta-Salmón H., Olivera A., Southgate P.C., Rangel-Dávalos C. (2006) The influence of culture method and culture period on quality of half-pearls ('mabe') from the winged pearl oyster Pteria sterna. Aquaculture, Vol. 254, pp. 269-274.

Shor R. (2007) From single source to global free market: the transformation of the cultured pearl industry. $G \uplus G$, Vol. 43, No. 3, pp. 200-226, http://dx.doi.org/10.5741/GEMS.43.3.200

Snedecor G.W., Cochran W.G. (1980) Statistical Methods. The Iowa State University Press, Ames, Iowa.

Snow M.R., Pring A., Self P., Losic D. (2004) The origin of the colour of pearls in iridescence from nano-composite structures of the nacre. American Mineralogist, Vol. 89, No. 10, pp. 1353 1358.

Taylor I., Strack E. (2008) Pearl production. In P.C. Southgate and J.S. Lucas, Eds., The Pearl Oyster. Elsevier, Oxford, UK. Chapter 8, pp. 273-302.

Tomaru Y., Udaka N., Kawabata Z., Nakano S. (2002a) Seasonal change of seston size distribution and phytoplankton composition in bivalve pearl oyster Pinctada fucata martensii culture farm. Hydrobiologia, Vol. 481, pp. 181-185

Tomaru Y., Kumatabara Y., Kawabata Z., Nakano S. (2002b) Effect of water temperature and chlorophyll abundance on shell growth of the Japanese pearl oyster, Pinctada fucata martensii, in suspended culture at different depths and site. Aquacultural Research, Vol. 33, No. 2, pp. 109-116, http://dx.doi.org/10.1046/ j.1365-2109.2002.00653.x

Tun T. (2000) A review of mass mortalities in pearl oyster. SPC Pearl Oyster Information Bulletin, Vol. 14, pp. 1-6.

Yamamoto K., Adachi S., Koube H. (1999) Effects of hypoxia on respiration in the pearl oyster, Pinctada fucata martensii. Aquaculture Science, Vol. 47, pp. 539-544, http://dx.doi.org/ 10.11233/aquaculturesci1953.47.539

Yukihira H., Lucas J.S., Klumpp D.W. (2000) Comparative effects of temperature on suspension feeding and energy budgets of the pearl oysters Pinctada margaritifera and P. maxima. Marine Ecology Progress Series, Vol. 195, pp. 179-188, http://dx.doi.org/10.3354/meps195179

Yukihira H., Lucas J.S., Klumpp D.W. (2006) The pearl oysters, Pinctada maxima and $P$. margaritifera, respond in different ways to culture in dissimilar environments. Aquaculture, Vol. 252, No. 2-4, pp. 208-224, http://dx.doi.org/10.1016/j.aquaculture.2005.06.032 